\title{
Imagination and literacy: Introduction to the special issue
}

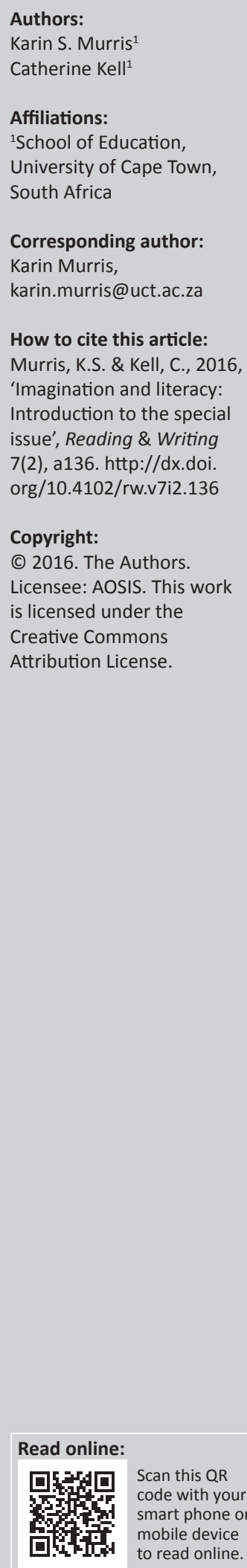

\section{Introduction}

The book The Little Prince by writer, poet and aviator Antoine de Saint-Exupery (published in 1943) has delighted readers of all ages and continues to fascinate and enthral until today. The story draws on Saint-Exupery's own experiences as a pilot who crashed his plane in the desert in 1935, but in the novella he recounts this moment as involving a meeting with a small and surprising interlocutor (the little prince). Much of the book consists of their conversations and of the narrator's experiences of being reminded through the dialogues with the little prince what he had lost in becoming adult. Like many young people in our classrooms, the little prince might not give the answers adults want to hear and instead asks the questions adults believe are of no consequence. The narrator takes us back to his own childhood when, at the age of six and inspired by a non-fiction book on the primeval forest, he drew a picture of a boa constrictor who had swallowed an animal, which appeared as the outline of a hat:

I showed my masterpiece to the grown-ups, and asked them whether the drawing frightened them. But they answered;

'Frightened? Why should anyone be frightened by a hat?'

My drawing was not a picture of a hat. It was a picture of a boa constrictor digesting an elephant. But since the grown-ups were not able to understand it, I made another drawing: I drew the inside of a boa constrictor, so that the grown-ups could see it clearly. They always need to have things explained. (De Saint-Exupery [1945] 1994:5-6)

Consequently, he was advised to refrain from drawing boas from the inside or the outside and to focus instead on geography, history, mathematics and literacy. Reflecting on his life, he observes that he has had countless encounters with many people who are concerned with matters of consequence, but:

Whenever I met one of them who seemed to me at all clearsighted, I tried the Experiment of showing them my Drawing Number One, which I have always kept. I would try to find out, so, if this was a person of true understanding. But, whoever it was, he, or she, would always say:

'That is a hat'.

Then I would never talk to that person about boa constrictors, or primeval forests, or stars. I would bring myself down to his level. I would talk to him about bridge, and golf and politics, and neckties. And the grown-up would be greatly pleased to have met such a sensible man. So I lived my life alone, without anyone I could really talk to. (De Saint- Exupery [1945] 1994:7)

In his very first encounter with the little prince after the plane crash, the tiny person asks him to please draw a sheep, with no reason or explanation for his curious request. After several attempts to make representational drawings of a sheep, rejected by the Little Prince as inadequate, the narrator draws a box with three holes in it and explains:

'This is only his box. The sheep you asked for is inside'.

I was very surprised to see a light break over the face of my young judge:

'That is exactly the way I wanted it! Do you think that this sheep will have to have a great deal of grass?'. 'Why?'

'Because where I live everything is very small...'

'There will surely be enough grass for him', I said. 'It is a very small sheep that I have given you'.

He bent his head over the drawing: 'Not so small that - Look! He has gone to sleep...'

And that is how I made the acquaintance of the little prince. (De Saint-Exupery [1945] 1994:10-11)

The novella is thus a potent meditation on imagination and the ways in which it is expressed, communicated and evaluated, as well as being a poignant reminder that growing up not only has 
its gains but also its losses. In this, the writer prefigures Kieran Egan's strong proposition that 'maturing' for many can involve the gradual demise of imaginative, metaphorical, embodied and original thinking (see for example Egan 1988, 1992, 1993, 1997). Egan, an educationalist who has published extensively on imagination and curriculum, was one of the sources of inspiration for the conference on Imagination and Literacy held in Cape Town in 2015, at which he delivered a keynote address and from which some of the articles included in this special edition are drawn.

\section{Why imagination and literacy?}

Some people associate the imagination with romantic ideas about young children and not with the real business of knowledge acquisition and communication. The imagination is often associated with aesthetic, playful, creative modes of being, knowing and re-presentation and viewed as belonging to creative subjects and disciplines such as the arts. But Egan (1992:3-4) argues that it is 'a common misunderstanding to regard the imagination as merely the capacity to produce images' - images as visualisations or the act of 'seeing in the mind'. Egan points out though, that while the Latin term imago does mean 'image', it also means 're-presentation', that is, a flexible rehearsal of possible situations in the mind and that it therefore involves reasoning. In its prospective sense it is about the capacity to think of the possible rather than just the actual. Greene (in Gennrich, this issue) describes it as the 'awareness of leaving something behind while reaching toward something new'. Greene (1995) also cites Dewey who describes imagination as "a "gateway" through which meanings derived from past experiences find their way into the present' (also in Gennrich, this issue), the 'conscious adjustment of the new and the old'.

We can conceptualise imagination as a central part of becoming literate, of reaching for something new in both expression and communication. And we can also conceptualise it as a central part of thinking differently about literacy education, about the literacy narratives and discourses we inhabit about our teaching and its effects.

Recent changes made by the Reading Association of South Africa (RASA) to the definition of literacy in this journal (Reading $\mathcal{E}$ Writing) are an expression of a profound rethinking of the nature of texts in literacy education and the emergence of socially just pedagogies that include the majority of our children who do not have instruction in their 'home' language. The definition now reads:

\footnotetext{
... the material form of texts is changing and ... literacy involves the ability to 'read' and 'write' more than just words. Literacy should therefore be seen as the ability to consume and produce texts in and across a range of semiotic modes such as, oral, visual, gestural, spatial and written.
}

Hence, this important rephrasing of the definition of literacy acknowledges the importance of other modes of expression and communication, like the visual, aural, gestural and the convergence of these modes in digital technologies. Each of these offers affordances for the work of the imagination.

\section{Imagination in the context of literacy education}

The theme for the conference and for this special edition of Reading $\mathcal{E}$ Writing arose in the first instance from noticing that, in the context of literacy education, the imagination as a meaning-making faculty receives remarkably little attention. Standardised national curricula are premised on assumptions about how people's minds develop and therefore how literacy should be taught - a focus that is mainly on cognitive development. Aristotelian philosophy, cognitive psychology and certain strands of sociology have informed a curriculum that includes pedagogical instruction from the 'simple' to the 'complex', the 'concrete' to the 'abstract', the 'familiar' to the 'unfamiliar', and moves from active manipulation to symbolic conceptualisation and from perception dominated thinking to conceptual freedom (Egan 2002). The 'essay-text' form of writing is viewed as the epitome of such moves and literacy instruction is geared to its achievement. These Western educational philosophies and orthodoxies have informed literacy curricula, the texts we choose for literacy (reading schemes, children's literature, adult education primers, comprehension tasks, the production of essays), sequencing and pacing of classes, how we make room for the body and for affect and emotion in teaching.

\section{The place of imagination in literacy education in South Africa}

A range of complex explanations and solutions have been advanced for the continued poor performance of South African students at all levels on national and international literacy and mathematics benchmark tests. Pointed out elsewhere (e.g. Murris \& Verbeek 2014), one argument that is increasingly gaining traction is that the country's teachers are deficient in content knowledge and that greater emphasis should be placed on 'the basics' of developing teacher knowledge (NEEDU [National Education Evaluation and Development Unit] 2013). While this is clearly a central problem, certain effects arise from this perspective, including a curriculum with highly prescribed, specified, sequenced and paced guidance regarding the content that should be taught in schools (see the National Curriculum Statement: DBE 2011). In addition, teachers' guides for textbooks as well as materials produced by the Department of Education provide teachers with scripted lessons in an attempt to address the lack of teacher content and pedagogic content knowledge (Murris \& Verbeek 2014). These textbooks on the one hand represent the world to learners, presenting language as almost the sole mode of communication. On the other, they encapsulate and privilege what is called a referential or denotational ideology of language in which the function of language is seen to involve simply its reference to things out there in the world, rather than other functions of language as identified, for example, by Jacobson (cited in Sebeok 1960), such as the poetic, the emotive, the phatic and the 
metalinguistic. In addition, this view marginalises other modes of communication such as the visual, audio and embodied. The resultant curriculum seems to leave little room for embodied and experiential learning, communicating and expressing in other modes such as the visual and does not foreground pedagogical relationships, all of which would be key to learning which involves the imagination. The words and concepts constituting disciplinary knowledge are in turn reproduced in standardised large-scale tests and exams, with the claim being made that systemic tests can be useful to measure progress and possibly lead to improvement in teaching and learning (Hoadley \& Muller 2016).

While many other explanations are advanced for educational failure, one common claim is that teachers often reproduce the pedagogies they themselves were exposed to, and that the dearth of reading materials in a wider range of genres in their own lives leaves them with little capacity to imagine and experiment with new literacy practices in their classrooms. This results in utilitarian perspectives on literacy based on the denotational view of language mentioned above, accompanied by skill and drill approaches and emphasis on the code-breaker role, as opposed to the text user or text analyst roles. The approach outlined above obviously attempts to address these 'deficiencies', but instead it provides a curriculum that fills the gaps and leaves minimal space for teacher initiative.

The publication of this special issue seems timely in view of the government's agenda to develop a standardised curriculum for the training of literacy teachers in higher education. Funded by the European Union, the Department of Higher Education and Technology (DHET) is currently organising seminars in Pretoria bringing together teacher educators from across South Africa to develop materials, programmes and research projects (Teaching \& Learning Development Capacity Improvement Programme) to improve initial teacher education (ITE). Taylor (2014:3) points out that it is not the idea that ITE is 'the next bashing boy, but to attempt to theorise its full educational function and, most important, to try to understand its role in the systemic reform required to close the apartheid gap'. We hope that the articles in this special issue can spark debate on the importance of imagination in teaching, learning and research to improve the quality of (higher) education.

\section{The articles in the special issue}

The theme of this special edition invited contributors to interpret, interrogate or deconstruct what imagination means in relation to literacy in the context of literacy education in the broad sense and across all phases of education. We did not receive many articles in response to our open Call for Papers that addressed the theme of imagination directly, but the ones we selected for this edition represent a spectrum of 'takes' on imagination and its place in teaching and learning literacy. Four of the five articles focus on imagination in relation to teacher education initiatives: one in a rural village in Uganda (Tembe and Reed), one in Nairobi (Shank) and two at the University of the Witwatersrand in
Johannesburg (Gennrich and Mendelowitz). Tembe and Reed also discuss the African Storybook (ASb) initiative, which they claim is an imaginative project in which reading materials in a wide range of African languages are produced and disseminated digitally. The only paper we received that reports research with children in classrooms, Murris and Thompson's paper, focuses at a micro level on the interactions between teachers and children in a classroom, in which imaginative responses to child-generated philosophical questions were elicited through drawings.

Drawing in particular on Egan's work and inspired by Paulo Freire's critical pedagogy, Shanks's article, Imagination, Waldorf, and Critical Literacies: Possibilities for Transformative Education in Mainstream Schools, reports on her work of integrating imaginative Waldorf-inspired approaches into mainstream Nairobi schools through a teacher-support programme. She takes up the difficult task of showing how the divergent thinking implied in critical literacies and imaginative Waldorf-inspired approaches can work in a government curriculum that demands convergent thinking.

'I got content with who I was': Rural teachers' encounters with new ways of practicing literacy by Toni Gennrich examines efforts within a teacher education programme at the University of the Witwatersrand in Johannesburg to expose teachers to working with different genres of text in order to challenge deeply entrenched ways of thinking about and valuing literacy, imagining the possibilities such genres afford for creative literacy practices, rather than operational and technicist ones.

Mendelowitz's article, You're in FunDzaland: Pre-service teachers (re) imagine audience on a creative writing course, shows how teacher students at a South African university engage with creative writing for a digital platform and in the process re-imagine the concept of 'audience'. Amidst calls for writing tasks in education that engage with real-life contexts and audiences, the intervention described here shows the intense imagination involved in such writing, and the conflicts and tensions that arise as different groups take up this task.

Focusing directly on the question of orthographies of literacy in a Ugandan language, Lunyole, whose orthography was only developed in 2003, Tembe and Reed's paper, Languaging in and about Lunyole: African Storybook materials as a catalyst for re-imagining literacy teaching and learning in two Ugandan schools, charts the developing agency amongst teachers as they engage with stories written in their own language. In this process they start to imagine that it is possible for them to teach their learners in their own language and to position their language alongside other powerful languages in Uganda.

Tembe and Reed's paper also introduces the ASb initiative, which they claim is an imaginative response to the Africa-wide shortage of texts in readers' primary languages. The ASb directly addresses the challenges of 
literacy development in contexts where reading materials just do not exist in the languages with which children are familiar, through the production of open access digital fictional and non-fiction stories that can be sourced from, translated, downloaded and uploaded onto a website. At present the project has resources in 65 African languages.

Murris and Thompson's article, Drawings as Imaginative Expressions of Philosophical Ideas in a Grade 2 South African literacy classroom, shows how children's drawings can be regarded as material-discursive manifestations of young children's developing philosophical ideas about death.

The articles also invite readers to examine the following key themes, amongst others.

\section{Imagination, agency and voice}

If imagination is about the capacity to envisage the possible, then agency must be implied. Relevant here is Appadurai's concept of 'the capacity to aspire' which he defines as 'a navigational capacity nurtured by the possibility of realworld conjectures and refutations' (2004:36). Central to this capacity to aspire is the concept of voice, which Appadurai counterposes with the concepts of 'exit' and 'loyalty' (following Hirschman 1970, in Appadurai 2014). Basically, this means that people exercise loyalty (and this often involves compliance), or if conditions are unfavourable, they choose exit. Voice is a capacity that intermediates the options of loyalty or exit, therefore linking closely with what we suggest is a key feature of imagination, the engagement with the possible, with the not-yet thought. The accomplishment of voice however is closely linked with the stock and the richness of the resources available for its articulation.

Both Gennrich and Tembe and Reed foreground the concept of agency in their papers. They each have a different 'take' on the concept. Gennrich grounds her theoretical framing in Bourdieu, linking the concept of imagination to a shift in habitus and questions whether shifting a deeply entrenched habitus is actually possible. She links this with Greene's (1995) idea that agency is one amongst four elements which are necessary for the release of the imagination and becoming 'wide awake to the world'. The two teachers who were the subjects of the intervention to 'shift habitus' certainly demonstrate their capacity to imagine new possibilities for their own personal literacy practices and in the teaching of their young learners.

Tembe and Reed focus more on how agency should be conceived less as a quality of actors but rather in its achievement in concrete settings through engagement and intention to 'bring about a future that is different from the present'. The Ugandan teachers they work with demonstrate new and previously unthought-of possibilities in their engagement with debates about Lunyole orthography and the possibilities for teaching in Lunyole.
Murris and Thompson engage with a notion of agency that moves beyond containment by the individualised body. Their paper deals with the theorisation of voice and is suggestive of what this might mean for agency that includes the force of the material - the notion of the environment as the 'third teacher'. Drawing on Loris Malaguzzi's metaphor of The Hundred Languages they argue how voice is not bounded by the human subject traditionally positioned in humanism as the knower (through symbolic systems such as language). In their take on philosophy for children, voice takes on a different ontological dimension that moves beyond identity, power and agency (Murris 2016). A perspective that is different from Shanks's paper in which the role of imagination in relation to identity is discussed, with imagination being seen as a 'conduit for identity formation'.

\section{Resources and repertoires}

As mentioned above, imagination and its articulation in voice are closely connected with the accessible and available material-semiotic resources and their configuration into repertoires. The papers here present a range of 'takes' on resources and repertoires. With regard to literacy, a wellknown model is Freebody and Luke's (2003) four resources model, which works to enable teachers to think of literacy beyond the teaching of discrete skills and sequenced programmes. In this model being literate is seen as engaging in four roles each with their own set of necessary resources for meaning making - being a 'code-breaker', being a 'text participant', a 'text user' and a 'text analyst'. When it comes to resources and repertoires that extend beyond the linguistic, Kell (2009:134) draws on the Vygotskyian concept of mediational means, which includes semiotic resources with their histories as modes and genres of communication, material objects and/or artefacts, as well as tools and technologies.

Gennrich's paper addresses the four resources model explicitly and shows how engagement by teachers in training with the genres of drama scripts and poetry frees up the teachers' own writing, their expression of affect and their sense of pleasure, signalling the space for imaginative work on the roles that are often neglected in our classrooms, those of text user and text analyst.

When it comes to linguistic resources, the availability of home language as a key resource in schooling has been identified as a crucial factor. Tembe and Reed's paper addresses this head on, showing the difficulties of building up curriculum and pedagogy in a language with a newly developed orthography. Shanks also mentions that Waldorf schools prefer their medium of instruction to be the home language.

Murris and Thompson's paper reveals how a focus on the visual in combination with an emphasis on philosophy enables children to engage intently with their own meaning making in relation to questions which go way beyond the normal comprehension questions required by formal schooling. The act of visualising frees up the children's space to develop and test their own theories about important 
questions and to negotiate these in engagement with others in the community of enquiry.

In her description of how the Waldorf curriculum works, Shanks's paper carefully outlines the repertoires and resources that children are exposed to at Waldorf schools. These include a strong emphasis on the story, on poems and songs, on the construction of objects and a preference for home language as a medium of instruction.

Mendelowitz's and Tembe and Reed's papers both draw attention to new resources in the form of digital platforms for producing and spreading stories in different languages. Mendelowitz's study outlines how students are set a task to write a story which is uploaded to the FunDza website for reading by its (potentially) vast real-life audience. The ASb project described by Tembe and Reed also enables users to upload and translate their own stories, which are then accessible for all.

\section{Divergence or convergence}

If the imagination is a thinking that resists closure and opens up unexpected lines of thought and new ideas (i.e. divergent thinking), then what are the tensions with a national literacy curriculum that assumes convergent thinking? Globally, curricula tend to focus on the production of right answers (known by the teachers and others in authority). What are the implications for how comprehension is conceptualised and the resources we use to teach it? In this regard, Shanks's discussion of how mainstream teachers can engage with Waldorf approaches is instructive. She carefully lays out the ways in which Waldorf education specifically encourages divergent thinking, counterposing this to the pedagogic practices to which the mainstream teachers are habituated.

Murris and Thompson also argue for divergent imaginative thinking through the practice of children asking philosophical questions about a picture book in a community of enquiry the pedagogy of philosophy for children (P4C).

\section{Conclusion}

In concluding, we turn to The Little Prince again as he gets us to entertain the thought that if we question our own cherished views we might open ourselves to completely new vistas on the landscapes of our lives, ones which draw in and on our own personal histories, memories, affect as well as cognition. We feel the narrator's own sense of surprise as the little prince challenges him yet again, helping him to find a secret space that meant much to him in his own past:

'The desert is beautiful', the little prince added.

And that was true. I have always loved the desert. One sits down on a desert sand dune, sees nothing, hears nothing. Yet through the silence something throbs, and gleams...

'What makes the desert beautiful', said the little prince, 'is that somewhere it hides a well...'

I was astonished by a sudden understanding of that mysterious radiation of the sands. When I as a little boy I lived in an old house, and legend told us that a treasure was buried there. To be sure, no one had ever known how to find it; perhaps no one had ever even looked for it. But it cast an enchantment over that house. My home was hiding a secret in the depths of its heart... (De Saint-Exupery [1945] 1994:73-74)

\section{References}

Appadurai, A., 2004, 'The capacity to aspire', in V. Rao \& M. Walton (eds.), Culture and public action, Stanford University Press, Stanford.

Department of Basic Education (DBE), 2011, National curriculum statement. Curriculum and assessment policy, foundation phase grades $R-3$. English home language, Government Printing Works, Pretoria, viewed n.d., from http://www. education.gov.za/

De Saint-Exupery, A. [1945] 1994, The Little Prince, transl. K. Woods, Heinemann, London.

Egan, K., 1988, Teaching as storytelling. An alternative approach to teaching and the curriculum, University of Western Ontario, Ontario, London.

Egan, K., 1992, Imagination in teaching and learning; ages 8-15, Routledge, London.

Egan, K., 1993, 'The other half of the child', in M. Lipman (ed.), Thinking, children and education, pp. 281-286, Kendall/Hunt, Montclair.

Egan, K., 1997, The educated mind: How cognitive tools shape our understanding, University of Chicago Press, Chicago.

Egan, K., 2002, Getting it wrong from the beginning: Our progressivist inheritance from Herbert Spencer, John Dewey, and Jean Piaget, Yale University Press, New Haven.

Freebody, P. \& Luke, A., 2003, 'Literacy as engaging with new forms of life: The "four roles" model', in G. Bull \& M. Anstey (eds.), The literacy Lexicon, pp. 52-57, Prentice Hall, Sydney.

Greene, M., 1995, Releasing the imagination: Essays on education, the arts, and social change, Jossey-Bass, San Francisco.

Hoadley, U. \& Muller, J., 2016, 'Visibility and differentiation: Systemic testing in a developing country context', Curriculum Journal. http://dx.doi.org/10.1080/0958 5176.2015.1129982

Kell, C., 2008, “"Making things happen": Literacy and agency in housing struggles in South Africa', Journal of Development Studies 44(2), 892-912.

Murris, K., 2016, The posthuman child: Educational transformation through philosophy with picturebooks, Routledge, London.

Murris, K. \& Verbeek, C., 2014, 'A foundation for foundation phase teacher education: Making wise educational judgements', South African Journal of Childhood Education 4(2), 1-17.

National Education Evaluation and Development Unit (NEEDU), 2013, 'Home', viewed n.d., from http://www.education.gov.za/NEEDU.aspx

Pahl, K. \& Rowsell, J., 2010, Artefactual literacies, Teachers College Press, New York.

Sebeok, T., 1960, Style in linguistics, MIT Press, Cambridge.

Taylor, N., 2014, 'Thinking, language and learning in initial teacher education'. Presentation to the Seminar Academic Depth and Rigour in ITE, University of the Witwatersrand, JET Education Services, 30-31th October 2014. 